\title{
Facilitating Group Cohesion Among Adolescents Through Challenge Course Experiences
}

\author{
$J$. Scott Glass and James M. Benshoff
}

\begin{abstract}
This article reports the results of a study which examined the effects of participation in a low-element challenge course on younger adolescents' perceptions of group cohesion. A pre and post test of the Group Cohesion Evaluation Questionnaire was administered to 167 participants. Results supported that group cohesion developed through the one-day, low-element challenge course experience, and that race, gender, and age of participants did not affect their perception of group cohesion.
\end{abstract}

Keywords: Low-element Challenge Course, Group Cohesion

In recent years, there has been an increase in the use of challenge course programs and activities, including low-element challenge courses, as interventions in clinical treatment facilities, as well as a treatment approach for adolescents with behavioral and social problems (Johnson, 1992), an approach to encourage personal growth (Herbert, 1996; Nassar - McMillan \& Cashwell, 1997), and as a method of building teams (Springett, 1987). Although participation in these activities is growing, there has been a paucity of research about the effects and effectiveness of these programs (Johnson). While outdoor challenge course practitioners and participants provide testimony that these experiences effect positive change, research findings to substantiate these claims are rare (Braverman, Brenner, Fretz, \& Desmond, 1990; Gillis, Bandoroff, Clapp, Gass, Rudolph \& Nadler, 1991; Johnson, 1992). Thus, there is a need for studies to further investigate the uses of challenge course programs and to examine possible outcomes of their implementation (Davis, Ray, \& Sayles, 1995).

J. Scott Glass, Ph.D., is an assistant professor in the Department of Human Services at Elan University, North Carolina. He can he reached at jglass@elon.edu. James M. Benshoff, Ph.D., is an associate professor in the Department of Counseling and Educational Development at the University of North Carolina at Greensboro.
One of the potential benefits for participants in challenge course programs is increased perception of group cohesion (Springett, 1987). Cohesiveness is one of the key factors in the development of a group (Griffin \& Pennscott, 1991) and an important variable for a variety of groups and different types of group processes (Evans \& Jarvis, 1980). In fact, the usefulness of cohesion as a mediator of group formation, maintenance, and productivity (Bollen \& Hoyle, 1990) has led some social scientists to deem it the most important small group variable (Golembiewski, 1962; Lott \& Lott, 1965). Although Valour compared development of group cohesiveness to development of the relationship between an individual client and counselor, he pointed out that cohesiveness in a group setting encompasses the group member's relationship not only to the group leader, but also to other group members (Griffin \& Pennscott).

Small group experiences can be critical for adolescents because of the increasingly important role peers play in their lives and the powerful impact of the peer group on adolescent behavior (Ingersol, 1989). Adolescent peer groups are not assembled randomly but are composed of individuals who share similar values, backgrounds and interests (Sprinthall \& Collins, 1988). Being part of a group is an important step in an adolescent's search for acceptance and identity.

Challenge programs provide structured activities and experiences designed to develop group cohesion by requiring group members to work together to accom- 
plish specific tasks. The impact of structured activities on group development has received considerable attention in the research literature (Stockton, Rohde, \& Haughey, 1992). Incorporating structure into a group, such as in a low-element challenge course program, generally includes presenting the group with a predetermined agenda, task, or exercise that provides a focal point for group participants (Stockton et al., 1992). Bednar, Melnick, and Kaul (1974) suggested that structure facilitates group work in the early stages by shifting responsibility in the group from members to the leader. This allows group members to be "free" to engage in higher risk behaviors, such as self-disclosure and interpersonal feedback (Stockton et al.).

The present study was developed to help address the need for more studies about the impact of participating in a challenge course on group development (Johnson, 1992) and was based on the assumption that group cohesion is as important a factor in challenge course programs as it is in other types of groups and group processes (Evans \& Jarvis, 1980). Prior to this study, no research can be found that has focused on the factor of group cohesion in challenge course programs, despite the increased popularity and use of these programs and despite the critical role of group process in these experiences. In addition, much of the existing research has been conducted with programs that occur over a week or more, such as Outward Bound (Harris, Mealy, Matthews, Lucas, \& Moczygemba, 1993), and with participants engaged in high ropes courses rather than participants in low-element challenge courses.

The purpose of this article is to present the results of a study that examined the effects of a one-day, low-element challenge course experience on the perception of group cohesion among participants. Because there is evidence that adolescent experiences may differ by gender (e.g., Archer \& McDonald, 1990; Garton \& Pratt, 1987; Shaw, Klieber, \& Caldwell, 1995), race (e.g., Philipp, 1998), and age (e.g., Erikson, 1968), this study further examined differences in perception of group cohesion by participant gender, age, and race.

\section{Group Cohesion}

Corey (1985) and Valour (1995) each view cohesiveness as a necessary yet insufficient condition for groups to progress to the working stage. Valour compared the development of cohesiveness in a group to the development of the relationship between a client and counselor in individual therapy. However, Valour pointed out that cohesiveness in a group setting is a broader concept than in individual counseling because it encompasses the group member's relationship, not only to the group leader, but also to the other group members (Griffin \&
Pennscott, 1991). Researchers have had a long-standing interest in the concept of group cohesion (Cota, Dion, \& Evans, 1993). Several reviews of research (e.g., Evans \& Jarvis, 1980) have identified group cohesion as an important variable for a variety of groups (e.g., therapy groups, living units, task groups, sport teams, and exercise groups) and different types of group processes (e.g., influence, conformity, communication, and behavior change). Carron and Brawley (2000) suggested that to understand the nature of groups we must first gain a better understanding of the nature of group cohesion.

The importance of considering group cohesion across disparate group types and group processes has been illustrated in a number of reviews (Evans \& Jarvis, 1980). Even with the considerable amount of empirical and conceptual work published on cohesion and its correlates, there remains a great deal of controversy among researchers regarding its definition and measurement (Albert, 1953; Beeber \& Schmitt, 1986; Budge, 1981; Dion \& Evans, 1992; Enoch \& McLemore, 1967; Hogg, 1992; Mudrack, 1989).

Currently, there are multiple models of cohesion with no single definition or model accepted by the majority of researchers interested in this construct. Central to the debate on defining cohesion is describing its structure (Cota, Dion, \& Evans, 1993; Enoch \& McLemore, 1967). Over the past five decades, social psychology researchers have examined the relationship between cohesion and other small group phenomena, ranging from group task performance (Bakeman \& Helmreich, 1975), to group therapy (Lieberman, Valour, \& Miles, 1973), to interpersonal communication within groups (Festinger, Schachter, \& Back, 1950), and intragroup pressure for uniformity (Festinger, Gerard, Hyomovitch, Kelley, \& Raven, 1952). Piper, Marrache, Lacroix, Richardson, and Jones' (1983) definition of cohesion as "a basic bond or uniting force" (p. 95) seems relevant to a broad range of small groups (Cota, Evans, Dion, Kilik, \& Longman, 1995), and therefore is used for the purposes of this paper.

Although cohesion often is described as one of the pivotal determinants of effective group therapy," (Rudman, Soldz, Derby, Feldstein, Springer, \& Davis. 1989, p.340) research on this topic has produced confusing and fragmented results (Kivlighan, Jr., \& Lilly, 1997). Mudrack (1989) researched the history of cohesion and determined that it has been dominated by confusion, inconsistency, and almost inexcusable sloppiness with regard to defining the construct" (p. 45). Several reasons are given for the problems that occur when attempting to empirically examine cohesion. These reasons include: (a) issues of definition and construct validity, (b) differences in how to best measure 
cohesion and analyze the resulting data, and (c) static versus dynamic conceptions of group cohesion (Kivlighan, Jr. \& Lilly).

\section{Challenge Courses}

Participation in adventure programs, such as a lowelement challenge course, has become increasingly popular in working with adolescents on life-skills issues such as communication, problem-solving and group cooperation (Monte \& Wodarski, 1997). The term "challenge course" has been used to encompass a wide array of programs used with diverse populations. All of these programs, however, are based on experiential education approaches in an outdoor setting, aimed mainly at increasing participants' self-esteem, trust in others, and risk-taking behaviors (Harris, Mealy, Matthews, Lucas, \& Moczygemba, 1993; Rohnke, 1989; Schoel, Prouty, \& Radcliffe, 1988). Generally, participants in these experiences are removed from their normal social contexts to engage in a number of physical activities that are not often related directly to the group's primary purpose with the aim of attaining new goals, both as individuals and as a group (Martin \& Davids, 1995).

While some elements of a low-element challenge course program focus on leadership abilities and others focus on communication skills, most activities emphasize group cohesion. Engaging in elements that focus on group cohesion typically requires few physical demands and encourages participants to share responsibility and solve problems as a team. While ropes courses focus more on individual accomplishments, low-element challenge courses require participants to display cooperation and utilize teamwork, and communication skills (Harris et al., 1993). Successful solutions to challenges depend upon the extent to which group members cooperate, trust, and communicate with one another. In addition, these group exercises impart lessons that participants later can apply to challenges in their personal lives.

Despite their increased popularity, challenge course programs have received little attention in the counseling literature, although goals of these programs parallel those of traditional counseling (George \& Christiani, 1995). Although research on outdoor adventure programs (Braverman et al., 1990; Johnson, 1992) has been limited, some positive outcomes have been reported. For example, Wagner and Roland (1992) discovered that overall functioning of adult groups improved with regards to their group process and interaction skills. Lieberman and DeVos (1982) conducted a study involving special-needs students with behavioral and adjustment difficulties, and found that youth who participated in adventure-based counseling activities in the school system improved their self-concept, decreased their anxiety, and showed an increase in positive attitudes toward school. Similarly, Sakofs and Schuurman (1991) found positive results in a one-year follow-up of a treatment program for adjudicated youth that integrated adventure therapy with a community-based component. One possible explanation for the success of challenge course programs is that they may be more effective at stimulating participants' feelings than traditional counseling approaches (Wood \& Gillis, 1979), a phenomenon attributed to the activities' combined use of physical, affective, and cognitive domains. While the focus is on the group, Herbert (1996) proposed that the stressful experiences that are likely to occur throughout the program also "serve as an impetus for individual change" (p. 6). The primary hypothesis for this study was that participation in a low-element challenge course would increase the self-reported perception of group cohesion among adolescent participants.

\section{Method}

\section{Participants}

Participants were 167 adolescents between the ages of 11 and 14 attending public schools in Eastern North Carolina who volunteered and received parental permission to participate in both the low-element challenge course program and this research study. The participant pool consisted of students at two junior high schools (i.e., grades 6, 7, and 8) and one elementary school (5th grade). There were 76 males $(45.5 \%)$ and 91 females (54.5\%). Eighty-six $(51.5 \%)$ of participants self-identified as being White, $63(37.7 \%)$ self-identified themselves as AfricanAmerican, and $18(10.8 \%)$ self-identified as Hispanic. The mean age of participants was 11.97 years.

Eight different group leaders, chosen according to availability and experience leading challenge course programs, served as facilitators of the challenge course program. Three of the leaders were female, five were male, and all were White. Years of group leadership experience with low-element challenge courses ranged from 3 to 15 years $(\mathrm{M}=7.63$ years, $S D=4.14)$. The age range for group leaders was 22 to 50 years of age $(\mathrm{M}=33.38, S D=10.69)$. Each group leader completed a leadership training program administered at the participating facility. This typically consisted of two days of experiential learning, with an experienced adventurebased leader guiding future leaders through activities while instructing them on how to lead and how to facilitate discussion afterwards. This training program prepared the leaders to work with any participant rather than one specific population.

\section{Procedure}

This study was conducted at an outdoor facility 
located in Eastern North Carolina. The challenge course at this site is a typical low-element program consisting of a series of initiative exercises each with clearly defined challenges. Each exercise is designed so that group members must employ cooperation and communication skills and work together to successfully complete the task. Teachers from a number of schools contact this facility each year to schedule a day for their classes to participate in the challenge course program. This study was conducted during six days of data collection, with one group of adolescents being studied per day.

Prior to groups arriving at the program site, six teachers were contacted to participate in this study; four of these teachers agreed that their students could participate. Upon receiving teacher consent to participate, 300 permission slips for this study were mailed to schools to be sent home with students for parent signatures. These slips notified parents that no risks were incurred by participating in the study, and that failure to turn in a permission slip to participate in the study in no way would affected adolescents' participation in the challenge course activities. Of 300 permission slips mailed, 230 were returned, for a response rate of $76.6 \%$. A separate parental consent form was required by the facility prior to student participation in the challenge course program.

Upon arriving at the facility, permission slips were collected and all school groups participated together in a number of large-group warm-up activities. After several of these exercises, participants were randomly assigned into smaller groups of 11-15 people, each composed of students attending the same school. These became the working groups for the day-long program. For example, a group of 60 students was asked to each find a partner and participate in a warm-up activity. Then each pair was asked to join another group of partners, creating 15 groups of four people each. Next, members of each group numbered off its members and separated into four different groups. This created four groups consisting of 15 members each. Participants were administered the Group Cohesion Evaluation Questionnaire (GCEQ) as a pre-test by the principal investigator (P1). Instructions for each administration of the instrument were explained by the PI. The role of the PI was to administer the instrument to the participants, answer questions, and inform group leaders of the testing schedule. The PI did not facilitate or participate in other aspects of the challenge course program during this study.

Participants engaged in the experiences of the challenge course throughout the remainder of the day. Each group participated in the challenge course for approximately six and a half hours. At the conclusion of the day, all participants were administered the GCEQ as a post-test, in an effort to assess participants' perceptions of group cohesion immediately following their challenge course experience. The PI was available also during this time to answer any questions participants might have had regarding the questionnaire. Only a couple of questions were asked by group members and each of those dealt with logistical issues (e.g., "Is 1 or 5 the best?" and, "Is this the group's opinion or mine?").

\section{Measures}

Participants' perceptions of group cohesion, the dependent variable in the study, were measured by the Group Cohesion Evaluation Questionnaire (GCEQ), an instrument created specifically for this study. The GCEQ was designed to assess group members' evaluations of how well their group was able to work together on the challenge course and whether the activities helped to foster a sense of group cohesion. The instrument consists of 9 items, whose answers are scored on a Likert-type scale ranging from 1 (Not at all like me/my group) to 4 (Exactly like me/my group). The GCEQ was developed because of a lack of appropriate materials to measure group connectedness or cohesion through a challenge course program for youth. Items on the GCEQ are similar to questions asked of participants during the debriefing process that follows each activity. The first step in developing the GCEQ was to review other instruments previously used to measure group cohesion, including The Group Attitude Scale (Evans \& Jarvis, 1986), Self-Report Family Inventory (Beavers, Hampson, \& Hulgus, 1985), Family Strengths Scale (Olson et al., 1985), Family Adaptability and Cohesion Evaluation Scales (Olson et al.), Family Well-Being Assessment (Caldwell, 1988), Family Adaptation Scale (Antonovsky \& Sourani, 1988), and the Family Relations Effectiveness Scale (Imig, 1981). None of these instruments were determined to be appropriate for use in the study.

Initially, 16 items were developed for the GCEQ, based on the literature and the types of items used in related instruments. Due to the age of the intended population (11-14 years old), it was decided that the instrument would be more easily understood and completed by participants if the number of items was reduced. Validity for the instrument was established by having seven expert raters (with an average of six years experience facilitating low-element challenge courses) rank items in terms of perceived importance and ability to measure group cohesion. The top nine items were retained in the GCEQ and used in this study to assess participants' perceptions of group cohesion (see Appendix A). Other variables used in this study (age, gender, and race) were obtained from responses to demographic data questionnaires administered to each participant. 


\section{Treatment}

Once participants arrived at the facility, they participated in approximately 30 minutes of warm-up exercises to help them become more comfortable in their new surroundings and in working together. After opening exercises, participants were randomly assigned to smaller groups (11-15 people) for the remainder of the challenge course program.

Each challenge was introduced to the group by the group facilitator. The directions were explained and safety issues were discussed for all elements. Safety issues included spotting and potential dangers. After each element was completed, leaders took time to process what had taken place, helping members find meaning through the previous activity and encouraging them to share appropriate personal information in an effort to develop group cohesion. Activities used during the course of the program were developed according to the Project Adventure model (Rohnke, 1984; Rohnke, 1989; Rohnke \& Butler, 1995). They included activities such as moon ball, tp shuffle, spider's web, king's ring, group juggling, mind field, and the swinging log.

\section{Results}

\section{Data Analysis}

The first step in analyzing data was to conduct a factor analysis of the GCEQ. Factor analysis is a statistical procedure used to analyze the interrelationships among a large number of variables and summarizes that information into a smaller set of common underlying dimensions or factors (Heppner, Kivlighan, \& Wampold, 1992). The fundamental aim of factor analysis is to search for common dimensions that underlie the original variables (Hair, Anderson, \& Tatham, 1987). Factor loadings for the nine items used in this study ranged from .72 to .82 , confirming that a single factor existed among the nine items. Reliability of the GCEQ was determined to be .91, using Cronbach's alpha.

The primary hypothesis for this study was that participation in a low-element challenge course would increase the self-reported perception of group cohesion among adolescent participants. To test this hypothesis, a matched-sample t-test was used to determine whether there was a significant change in participants' pre and post-test mean scores on the GCEQ (indicating change in perception of group cohesion). For this study, 167 participants completed both pre and post-tests. The results are displayed in Table 1. A statistically significant increase in mean scores from pre to post-tests $(+4.35)$ was found, suggesting that participants did perceive increased group cohesion as a result of participation in the challenge course program. Of the 230 participants returning permission forms, 63 were randomly selected to answer only the post-test in order to determine if completing the pretest had a significant effect on posttest results. These results were not significant.

Stepwise linear regression was used to test the effects of these independent variables on group cohesion. The results are displayed in Table 2. Results for those who chose to participate did not reveal significant differences in the post-test scores by age, gender, or race; these independent variables explained less than one percent of the variation in post-test scores. Thus, age, race, and gender of participants were not found to significantly affect how they perceived the development of group cohesion in the challenge course experience.

Means and standard deviations for each independent variable are provided in Tables $3 \mathrm{a}, 3 \mathrm{~b}$, and $3 \mathrm{c}$. These data reveal how participants with each independent variable scored on the GCEQ. The most dramatic change among age was found for adolescents 14 years old. As a group, they had a difference in means of 6.49 between pretest and post-test scores. Although this population showed the greatest increase among age groups, their post-test scores were similar to other age groups. Thus, the age of participants was not found to have a statistically significant effect on the post-test results. Likewise, results based on gender did not show a significant difference in scores on the GCEQ. In addition, race did not have a statistically significant effect on the post-test results.

\section{Discussion}

Results of this study suggest that participation in a one-day, low-element challenge course can develop group cohesion among adolescent participants. These results may be due to the nature of the challenge course program itself which offers participants structured group experiences in which the leader provides direction and instructions but also shifts responsibility to group members for successful completion of activities. This allows group members to then be "free" to engage in other behaviors such as self-disclosure and interpersonal feedback (Stockton et al., 1992) that help to foster group cohesion.

Another possible explanation for the increase in group cohesion may be the focus of group discussions on the members themselves and how challenge activities may relate to their everyday lives. Rudman, Soldz, Derby, Davis, and Merry (1993) found that cohesive interaction during the earliest stages of group development is characterized by group members sharing information with one another about their lives outside of the group. In contrast, they found too much focus on the group leader during early stages of groups to be counter- 
Table 1. Results of T-tests for Matched Samples $(\mathrm{N}=167)$

\begin{tabular}{cccc}
\hline Variable & Mean & Std. Dev. & T-test Sig. \\
\hline PRE-TEST & 28.31 & 6.28 & \\
POST-TEST & 32.66 & 4.96 & 9.02
\end{tabular}

cohesive. Challenge courses encourage interaction and self-disclosure among participants in the early stages of group process, keeping the focus off of the group leader who serves more as a guide and facilitator for the group.

Although other studies (e.g., Lee, 1972) have found race to be an important variable in leisure preferences, results of this study suggest that participation in a lowelement challenge course may offer one method for increasing group cohesion among participants from different racial backgrounds. Low-element challenge course programs requires that participants from different racial and ethnic backgrounds work together to help their groups succeed. Processes used in low-element challenge courses may help to lessen race-based discrimination and help each member of the small group feel connected to and a part of the group. Similarly, the finding of no significant differences in perception of group cohesion by age or gender suggests that the lowelement challenge course program can cross barriers and help to develop group cohesion with a variety of people who tend to respond similarly to the process.

\section{Recommendations}

This study found support for common claims that low-element challenge courses can help different kinds of groups experience higher levels of perceived group cohesion, while perhaps minimizing the effects of variables such as race, gender, and age. Future investigators should examine the impact of challenge course experiences on participants of different ages, ethnic backgrounds, genders, and geographic locations. While this study examined differences by age, gender, and race, relatively small sample sizes (and the limited age range of participants) may have prevented finding differences that would appear in a study with a larger, more diverse sample. Future studies also might investigate the effectiveness of low-element challenge courses in increasing group cohesion among participants in age groups other than those examined in this study (e.g., adults of different ages and younger children). In addition, future research might investigate the minimum age for children to experience benefits from these programs. For example, processes used in this type of program may be too complicated for children, even younger adolescents,
Table 2. Summary of Stepwise Linear Regression Analysis for Variables Affecting Participants' Perceptions of Group Cohesion $(\mathrm{N}=167)$

\begin{tabular}{ccccc}
\hline \multicolumn{1}{c}{ Variable } & B & SE B & Beta & Sig. \\
Step 1 Gender & -.64 & .65 & -.06 & .33 \\
Step 2 Gender & & & & \\
Gender & -.68 & .65 & -.07 & .30 \\
Age & .38 & .37 & .07 & .31 \\
Step 3 & & & & \\
Gender & .67 & .66 & -.07 & .31 \\
Race & .17 & .48 & .02 & .72 \\
Age & .36 & .38 & .06 & .34
\end{tabular}

Note. $\mathrm{R}^{2}=.004$ for Step $1 ; \mathrm{R}^{2}=.009$ for Step 2;

$\mathrm{R}^{2}=.009$ for Step 3 .

to understand or experience benefits.

Future studies also might examine, more closely, the role of the group leader in the development of cohesion through the challenge course experience. In this study, all group leaders were White, although there was a quite a range in age. What effects might race, age, or gender of group leader have on group cohesion? Also, how much can, or should, race, age, and gender of group leaders match demographics of their groups? Further, this study did not investigate any effects of group leaders' personal characteristics or particular leadership styles.

In addition, the relationship of the group leader to members can be an important factor in group cohesion that is worthy of further investigation. The relationship between leader behaviors and cohesion in natural groups has received little empirical attention to date (Shields, Gardner, Bredemeier, \& Bostro, 1997). While leadership style has been the focus of several studies (e.g., Shields et al., 1997; Rose \& Bednar, 1980), little has been written about the effects of leadership style in challenge courses and the nature of participants' experiences. Low-element challenge courses train leaders to provide strong instruction, social support, and positive feedback to the groups participating in the activities. Improved understanding of the role of group leaders in facilitating group cohesion could aid low-element challenge courses in training and evaluating their staff, resulting in challenge course programs that may offer greater benefit to participants.

Another important step to examine, in more detail, is the processes of the challenge course program to determine what has the greatest effect on adolescents' perceptions of group cohesion. Future research might look at the sequence of activities that each small group experiences to determine if the order of exercises plays 
a role in perceptions of group cohesion. It is possible that variations in sequencing of activities could affect the manner in which a group bonds and becomes more cohesive. Even slight alterations between groups might have some effects that warrant investigation. For example, if an adolescent group participating in the low-element challenge course attempts an activity that the group members feel is too challenging for them early in the day, their response to the activity may be more harmful to the group than it would be later in the day, when the group has had more opportunities in problemsolving as a unit.

Finally, this study demonstrated the value of the Group Cohesion Evaluation Questionnaire (GCEQ) as a reliable and valid instrument worthy of use in future studies of group cohesion. Future researchers also should consider using multiple measures to assess treatment effects and understand the group processes that occur in challenge course programs. Use of qualitative methodology, such as structured interviews or debriefing of groups or individual group members, could contribute significantly to the understanding of how members experience these groups.

\section{Limitations}

It is important to acknowledge several limitations of this study. First, because the sample was drawn from schools in one geographic region, generalizability of findings to other geographic regions may be limited. Second, the low-element challenge course implemented for this study represents only one type of outdoor adventure program; thus, reactions of participants in other kinds of programs may differ. There also were limitations related to distribution of participants in the study by age, as the majority $(47 \%)$ of participants were 12 years old, while only $19(8.3 \%)$ were 14 years old. Although participants were assigned randomly to groups, they were selected from intact school classes; thus, the degree to which a particular teacher's class group was already cohesive could affect findings. The lack of a control group limits conclusions that the increased in perceived group cohesion was attributal to the one-day challenge course experience. Finally, as with other experiential education programs, there is no indication that increases in group cohesion generalized back to participants' school setting or their daily lives.

\section{Conclusion}

The use of challenge course activities among adolescents with behavioral and social problems has become increasingly common, yet has not been matched by an increase in research in this area (Johnson, 1992). This study found that participation in a low-element
Table 3a. Means and Standard Deviations of Age

\begin{tabular}{cccc}
\hline AGE & & Pre-test & Post-test \\
\hline 11 & $N$ & 59 & 59 \\
& Mean & 28.0000 & 32.2034 \\
& Std. Dev. & 6.0629 & 5.4734 \\
\hline \multirow{2}{*}{12} & $\mathrm{~N}$ & 66 & 108 \\
& Mean & 28.7424 & 32.1019 \\
& Std. Dev. & 6.5123 & 4.6140 \\
\hline \multirow{4}{*}{13} & $\mathrm{~N}$ & 30 & 44 \\
& Mean & 28.3667 & 32.3409 \\
& Std. Dev. & 5.8101 & 5.4770 \\
\hline \multirow{2}{*}{14} & $\mathrm{~N}$ & 12 & 19 \\
& Mean & 27.2500 & 33.7368 \\
& Std. Dev. & 7.6649 & 3.5252 \\
\hline
\end{tabular}

Table 3b. Means and Standard Deviations of Gender

\begin{tabular}{lccc}
\hline GENDER & & Pre-test & Post-test \\
\hline Male & $N$ & 76 & 108 \\
& Mean & 28.5263 & 32.6481 \\
& Std. Dev. & 5.9988 & 4.5577 \\
Female & $N$ & 91 & 122 \\
& Mean & 28.1209 & 32.0082 \\
& Std. Dev. & 6.5317 & 5.2436 \\
& & &
\end{tabular}

Table 3c. Means and Standard Deviations of Race

\begin{tabular}{lccc}
\hline RACE & & Pre-test & Post-test \\
\hline White & $\mathrm{N}$ & 86 & 111 \\
& Mean & 28.0581 & 32.1261 \\
& Std. Dev. & 6.2447 & 5.3752 \\
\hline African & $\mathrm{N}$ & 86 & 91 \\
American & Mean & 29.1111 & 32.4505 \\
& Std. Dev. & 6.1934 & 4.5686 \\
\hline Hispanic & $\mathrm{N}$ & 18 & 28 \\
& Mean & 26.6667 & 32.5714 \\
& Std. Dev. & 6.6774 & 4.3413 \\
\hline
\end{tabular}


challenge course program increased the perception of group cohesion among normal adolescents between the ages of 11 and 14. In addition, findings from this study suggest that adolescent participants perceived an increase in group cohesion through the experience regardless of their age, race, and gender. Results of this study lend support to the use of low-element challenge course experiences to foster group cohesion, and suggest that more studies would be helpful.

\section{Appendix A-Group Cohesion Evaluation Questionnaire}

Group \#

Gender: Male Female

Race:

Age:

\section{GROUP COHESION EVALUATION QUESTIONNAIRE}

Please tell us which of the following statements best describe you and your group.

$\begin{array}{llll}\text { NOT AT ALL } & \text { A LITTLE } & \text { A LOT } & \text { EXACTLY } \\ \text { LIKE ME/MY } & \text { LIKE ME/ } & \text { LIKE ME/ } & \text { LIKE ME/ } \\ \text { GROUP } & \text { MY GROUP } & \text { MY GROUP } & \text { MY GROUP }\end{array}$

1. We get along well together.

1

2. We feel good about our team.

3. We enjoy helping each other.

4. We stick together during the challenges.

5. I feel like my group will keep me safe.

6. We encourage each other in the challenges.

7. I feel like I fit in my group.

8. I want to work on more challenges with my group.

9. We help each other on the challenges.

$\begin{array}{llll}1 & 2 & 3 & 4 \\ 1 & 2 & 3 & 4 \\ 1 & 2 & 3 & 4 \\ 1 & 2 & 3 & 4 \\ 1 & 2 & 3 & 4 \\ 1 & 2 & 3 & 4 \\ 1 & 2 & 3 & 4 \\ 1 & 2 & 3 & 4 \\ 1 & 2 & 3 & \end{array}$

4

4

4

4

4

4

4

4

\section{References}

Albert, R. S. (1953). Comments on the scientific function of the concept of cohesiveness. American Journal of Sociology, 59, 231-234.

Antonovsky, A., \& Sourani, T. (1988). Family sense of coherence and family adaptation. Journal of Marriage and Family, 50, 79-92.

Archer, J., \& McDonald, M. (1990). Gender roles and sports in adolescent girls. Leisure Studies, 9, 224-240.

Bakeman, R., \& Helmreich, R. (1975). Cohesiveness and performance: Covariation and causality in an undersea environment. Journal of Experimental Social Psychology, 11, 478-489.
Beavers, W. R., Hampson, R. B., \& Hulgus, Y. F. (1985). The Beavers' systems approach to family assessment. Family Procedures, 24, 398-405.

Bednar, R. L., Melnick, J., \& Kaul, T. J. (1974). Risk, responsibility, and structure: A conceptual framework for initiating group counseling and psychotherapy. Journal of Counseling Psychology, 21, 31-37.

Beeber, L. S., \& Schmitt, M. H. (1986). Cohesiveness in groups: A concept in search of a definition. Advances in Nursing Science, 8, 111.

Bollen, K. A., \& Hoyle, R. H. (1990). Perceived cohesion: A conceptual Bollen, K. A., \& Hoyle, R. H. (1990). Perceived cohesion: A conceptual and empirical examination. Social Forces, 69, 479504. 
Budge, S. (1981). Group cohesiveness reexamined. Group, 5, 10-18.

Rudman, S. H., Soldz, S., Derby, A., Davis, M., \& Merry, J. (1993). What is cohesiveness? An empirical investigation. Small Group Research, 24, 199-216.

Rudman, S. H., Soldz, S., Derby, A., Feldstein, M., Springer, T., \& Davis, M. S. (1989). Cohesion alliance and outcome in group psychotherapy. Psychiatry, 52, 339-350.

Braverman, M., Brenner, J., Fretz, P., \& Desmond, D. (1990). Three approaches to evaluation: A ropes course illustration. Journal of Experiential Education, 13, 23-30.

Caldwell, S. M. (1988). Measuring family well-being: Conceptual model, reliability, validity, and use. In C. F. Waltz, \& O. L. Strickland (Eds.), Measurement of clinical and educational nursing outcomes: Vol 1. Client-centered outcomes (pp. 396-416). New York: Springer.

Carron, A. V., \& Brawley, L. R. (2000). Cohesion. Small Group Research, 31, 89-106.

Corey, G. (1985). Theory and practice of group counseling (2nd ed.). Monterey, CA: Brooks/Cole.

Cota, A. A., Dion, K. L., \& Evans, C. R. (1993). A reexamination of the structure of the Gross Cohesiveness Scale. Educational and Psychological Measurement, 53, 499-506.

Cota, A. A., Evans, C. R., Dion, K. L., Kilik, L., \& Longman, R. S. (1995). The structure of group cohesion. Personality and Social Personality and Social Psychology Bulletin, 21, 572-580.

Davis, D., Ray, J., \& Sayles, C. (1995). Ropes course training for youth in a rural setting: "At first 1 thought it was going to be boring..." Child and Adolescent Social Work Journal, 12, 445-463.

Dion, K. L., \& Evans, C. R. (1992). On cohesiveness: Reply to Keyton and other critics of the construct. Small Group Research, 23, 242250.

Enoch, J. R., \& McLemore, S. D. (1967). On the meaning of group cohesion. Southwestern Social Science Quarterly, 48, 174-182.

Erikson, E. H. (1968). Identity: Youth and crisis. New York: Norton.

Evans, N. J., \& Jarvis, P. A. (1980). Group cohesion: A review and reevaluation. Small Group Behavior, 11, 359-370.

Evans, N. J., \& Jarvis, P. A. (1986). The Group Attitude Scale: A measure of attraction to group. Small Group Behavior, 2, 203-216.

Festinger, L., Gerard, H. B., Hyomovitch, B., Kelley, H. H., \& Raven, B. (1952). The influence process in the presence of extreme deviates. Human Relations, 2, 37-46.

Festinger, L., Schachter, S., \& Back, K. (1950). Social pressures in informal group study of human factors in housing. New York: Harper \& Row.

Garton, A. F., \& Pratt, C. (1987). Participation and interest in leisure activities by adolescent schoolchildren. Journal of Adolescence, 10, 341-351.

George, R. L., \& Christiani, T. S. (1995). Counseling theory and pracCounseling theory and practice (4th ed.). Needham Heights, MA: Allyn \& Bacon.

Gillis, H., Bandoroff, S., Clapp, C., Gass, M., Rudolph, S., \& Nadler, R. (1991). Family adventure questionnaire: Results and discussion. In Proceedings of the international Conference and Workshop Summaries Book of the International Association for Experiential
Education, 19th, Lake Junaluska, NC, October 24-27.

Golembiewski, R. T. (1962). The small group. Chicago: University of Chicago Press.

Griffin, B., \& Pennscott, W. (1991). The development of cohesiveness and self-esteem in an experientially oriented training group. TACD Journal, 19, 53-58.

Hair, J. F., Jr., Anderson, R. E., \& Tatham, R. L. (1987). Multivariate data analysis: With readings (2nd ed.). New York: Macmillan.

Harris, P. M., Mealy, L., Matthews, H., Lucas, R., \& Moczygemba, M. (1993). A wilderness challenge program as correctional treatment. Journal of Offender Rehabilitation, 19, 149-164.

Heppner, P. P., Kivlighan, D. M., Jr., \& Wampold, B. E. (1992). Research design in counseling. Pacific Grove, CA: Brooks/Cole.

Herbert, T. (1996). Use of adventure-based counseling programs for persons with disabilities. Journal of Rehabilitation, 62, 3-9.

Hogg, M. A. (1992). The social psychology of group cohesiveness: From attraction to social identity. New York: New York University.

'rig, D. R. (1981). Accumulated stress of life changes and interpersonal effectiveness in the family. Family Relations, 30, 367-371.

Ingersol, G. M. (1989). Adolescents. Englewood Cliffs, NJ: Prentice Hall.

Johnson, J. (1992). Adventure therapy: The ropes-wilderness connection. Therapeutic Recreation Journal, 3, 17-26.

Kivlighan, Jr., D. M., \& Lilly, R. L. (1997). Developmental changes in group climate as they relate to therapeutic gain. Group Dynamics: Theory, Research, and Practice, 1, 208-221.

Lee, R. G. (1972). The social definition of outdoor recreation places. In W. R. Burch, N. Cheek, \& L. Taylor (Eds.), Social behavior, natural resources, and environment resources, and environment (pp. 68-84). New York: Harper \& Row.

Lieberman, M. A., \& DeVos, E. (1982 September). Adventure-based counseling final evaluation report. Hamilton, MA: Project Adventure.

Lieberman, M. A., Valour, I. D., \& Miles, M. B. (1973). Encounter group facts. New York: Basic Books.

Lott, A. J., \& Lott, B. E. (1965). Group cohesiveness as interpersonal attraction: A review of relationships with antecedents and consequent variables. Psychological Bulletin, 64, 259-309.

Martin, R., \& Davids, K. (1995). The effects of group development techniques on a professional athletic team. The Journal of Social Psychology, 135, 533-535.

Moote, G. T., Jr., \& Wodarski, J. S. (1997). The acquisition of life skills through adventure-based activities and programs: A review of the literature. Adolescence, 32, 143-167.

Mudrack, P. E. (1989). Defining group cohesiveness: A legacy of confusion? Small Group Behavior, 20, 37-49.

Nassar-McMillan, S. C., \& Cashwell, C. S. (1997). Building self-esteem of children and adolescents through adventure-based counseling. Journal of Humanistic Counseling Education \& Development, 36, 59-67.

Olson, D. H., McCubbin, H. I., Barnes, H., Larsen, A., Muxem, M., \& Wilson, M. (1985). Family inventories. St. Paul, MN: University of Minnesota, Family Social Science. 
Philipp, S. F. (1998). Race and gender differences in adolescent peer group approval of leisure activities. Journal of Leisure Research, 30, 214-232.

Piper, W. E., Marrache, M., Lacroix, R., Richardsen, A. M., \& Jones, B. D. (1983). Cohesion as a basic bond in groups. Human Relations, 36, 93-108.

Rohnke, K. (1984). Silver bullets: A guide to initiative problems, adventure games and trust activities. Dubuque, IA: Kendall/Hunt.

Rohnke, K. (1989). Cowtails and cobras fl: A guide to games, initiatives, ropes courses, \& adventure curriculum. Dubuque, IA: Kendall/Hunt.

Rohnke, K., \& Butler, S. (1995). Quicksilver: Adventure games, initiative problems, trust activities and a guide to effective leadership. Dubuque, IA: Kendall/Hunt.

Rose, G. S., \& Bednar, R. L. (1980). Effects of positive and negative self-disclosure and feedback on early group development. Journal of Counseling Psychology, 27, 63-70.

Sakofs, M., \& Schuurman, D. (1991). Assessing the impact of the Wilderness Alternative for youth program. Greenwich, CT: Outward Bound

Schoel, J., Prouty, D., \& Radcliffe, P. (1988). Islands of healing: A guide to adventure based counseling. Hamilton, MA: Project Adventure.
Shaw, S. M, Kleiber, D. A., \& Caldwell, L. L. (1995). Leisure and Identity formation in male and female adolescents: A preliminary examination. Journal of Leisure Research, 27, 245-263.

Shields, D. L. L., Gardner, D. E., Bredemeier, B. J. L., \& Bostro, A. (1997). The relationship between leadership behaviors and group cohesion in team sports. The Journal of Psychology, 131, 196210.

Springett, N. R. (1987). The evaluation of development training courses. Unpublished master's thesis, University of Sheffield, England.

Sprinthall, N. A., \& Collins, W. A. (1988). Adolescent psychology: A developmental view. New York: Random House.

Stockton, R., Rohde, R. I., \& Haughey, J. (1992). The effects of structured group exercises on cohesion, engagement, avoidance, and conflict. Small Group Research, 23, 155-168.

Wagner, R., \& Roland, C. (1992). How effective is outdoor training? Training and Development, 7, 61-66.

Wood, D. E., \& Gillis, J. C. (1979). Adventure education. Washington, DC: National Education Association.

Valor, I. D. (1995). The theory and practice of group psychotherapy (4th ed.). New York: Basic Books. 